\title{
A Three-Year Retrospective Study of the World Health Organisation Safety Checklist Compliance in a Comprehensive Specialized Hospital in Debre Tabor, North Central Ethiopia
}

This article was published in the following Dove Press journal: Open Access Surgery

\author{
Abebe Tiruneh $(11)$ \\ Tikuneh Yetneberk (D) \\ Department of Anesthesia, Debre Tabor \\ University, Debre Tabor, Amhara, \\ Ethiopia
}

\begin{abstract}
Introduction: World Health Organization (WHO) surgical safety checklist implementation is important for good outcomes of surgical patients. WHO surgical safety checklist has three components (sign in, time out, and sign out) and has to be applied before the surgery and before the transfer of the patient to the recovery room. WHO surgical safety checklist was implemented in $25 \%-65 \%$ among the surgical team in different hospitals.

Objective: The objective of this study was to assess the compliance and completeness of the WHO surgical safety checklist at Debre Tabor Comprehensive Specialized Hospital.

Methods: We used a three-year retrospective survey from July 2017 to July 2020 based on a chart review of surgical patient charts. We include a total of 3460 surgical patient charts for three years period, and from this, we got a surgical safety checklist from 2842 surgical patient charts. We analyzed the data by using SPSS version 21. And finally, the descriptive statistics presented.

Results: From this study, the compliance of the WHO surgical safety checklist was $82.1 \%$ (2842/3460). From the parts of the checklist, sign in, time out, and sign out were implemented in $85.1 \%$ (2420/2842), 43.9\% (1248/2842), and 57.7\% (1642/2842), respectively. The overall completeness of the checklist (all boxes ticked off) was 30.4\% (864/2842).

Conclusion: The compliance of the WHO surgical safety checklist was good but their completeness was still poor so it needs attention and follow-up for better completeness of the WHO surgical safety checklist.
\end{abstract}

Keywords: completeness, compliance, safety checklist

\section{Introduction}

Surgical service is provided for patients that need surgery across the world. Surgery and Anesthesia are given for therapeutic, palliative, and diagnostic purposes. While during the surgery and anesthesia services there are several complications including wrong-site operation, prolonged hospital stay, morbidity, and mortality, for prevention or reduction of surgery and anesthesia-related complications use of World Health Organization (WHO) surgical safety checklist is the main one. ${ }^{1}$ WHO surgical safety checklist implementation is important and health professionals also aware that it is important and has to be applied. ${ }^{2}$ WHO surgical safety checklist was practiced in $25 \%-65 \%$ among Anesthetists based on different factors. ${ }^{3}$

Appropriate use of the WHO surgical safety checklist can reduce surgical patient morbidity and mortality. ${ }^{1}$
Correspondence: Abebe Tiruneh

Department of Anesthesia, Debre Tabor

University, Debre Tabor, Amhara 272,

Ethiopia

Tel $+25 I-918028440$

Email abebetiruneh795@yahoo.com

Open Access Surgery 2020:13 95-99 
After the use of the checklist surgical patient complications including mortality was reduced. ${ }^{4}$ The use of the checklist also helps health professionals to improve safety, patient communications, and to develop a safety culture. ${ }^{5}$

The compliance and completeness of the WHO Surgical safety checklist were more practiced in Elective surgery. ${ }^{6}$

The importance of the WHO surgical safety checklist for surgical patients is important but the practice was poor even the documented one better than the performed with the components of sign in, time out, and sign out components. $^{7}$

From one Ethiopian hospital, the completion of the WHO surgical safety checklist was $20 \%$, the most missed part from the checklist was 'site marked' and 'recovery concern' and they said that communication difficulties and staff turnover were the reason for the poor practice of WHO surgical safety checklist, ${ }^{8}$ other studies also revealed that lack of previous training and poor communication with the surgical team were the factors for the incompleteness of the checklist. ${ }^{9}$ Use of the WHO surgical safety checklist for surgical patients and attached it on the surgical patient chart was recommended.

The main aim of this study was to assess the compliance and completeness of the WHO surgical safety checklist at Debre Tabor Comprehensive Specialized Hospital for surgical patients.

\section{Methods and Materials}

A retrospective cross-sectional survey was conducted to identify the compliance and completeness of the WHO surgical safety checklist for surgical patients at Debre Tabor Comprehensive Specialized Hospital from July2017to July 2020. Debre Tabor is a town in NorthCentral Ethiopia, found $667 \mathrm{~km}$ away from the capital city of Ethiopia (Addis Ababa), 100 kilometers Southeast of Gondar, and 50 kilometers East of Lake Tana. This town has an altitude and longitude of $11^{\circ} 51^{\prime} \mathrm{N} 38^{\circ} 1^{\prime} \mathrm{ED}$ with an elevation of 2706 meters (8878 ft) above sea level. Based on the population growth projection the current total population of the zone is about $2,578,906$. This hospital gives surgical services for the zonal population and neighbor woredas. This hospital gives major surgical services, orthopedics surgery gynecologic surgery, and obstetric surgery. The use of the WHO surgical safety checklist was recommended in all surgical patients ${ }^{10}$ and it needs the involvement of all surgical teams in this specific hospital (Anesthetists, surgeons, and nurses). The WHO checklist consists of three main parts, Sign-in is done before administering Anaesthesia to the patient, Timeout is done before patient skin incision, and Sign-out is done before the transfer of the operated patient to the recovery room. At each of these components, the surgical team will be informed on important information checked, communicated, and reaches in agreement for all the surgical team. We assessed the use of the WHO surgical safety checklist to surgical patients from all surgical patients by checking the checklist on the surgical patient's chart. The data collectors check the compliance, and completeness of the checklist on the three components and the content on each part (sign in, time out, and sign out). Other than this we were not involved during the implementation of the checklist rather reviewing the patient's chart after the procedure was performed and the patient discharged from the hospital. Consent was waived by Debre Tabor University ethical review committee since we used secondary data. The data were collected after getting permission from the Debre Tabor Comprehensive Specialized Hospital. This study complied with the declaration of Helsinki. We collect the data from the surgical patient charts by the checklist and analyzed using the SPSS version 21 for describing the result. The WHO surgical safety checklist was open access and freely available at this website (www.who.int/safesurgery). A total of three-year hospital data were used for analysis. We analyzed a total of 3460 surgical patient charts. All data were accessed, compiled, and secured by avoiding personal identifications rather we used only the surgical patient registration card number and all the data were accessed for only the authors. Anonymity and confidentiality were secured at every step of this research. The descriptive data were summarized by text and tables.

\section{Result}

We analyzed 3 years of surgical patients WHO surgical safety checklist with a total of 3460 patient charts. From these 2842 charts, we have a WHO surgical safety checklist within it and it revealed that the compliance of the WHO surgical safety checklist was $82.1 \%(2842 / 3460)$ (the surgical patient chart has surgical safety checklist and one or more part of the components were implemented). From the used checklist only 30.4\% (864/2842) of the surgical patient chart was complete (ie all the components ticked off) and the remaining $69.6 \%$ of the checklist partially complete. And all the checklist ticked and signed by nurses at the operation theater. 
From each component of the checklist patient identity, site, procedure, and consent, and the site marked were the most ticked components from the checklist (Table 1), but What are the key concerns for recovery and management of this patient was the least ticked box from the checklist (Table 3).

From the three components of the checklist sign in $85.1 \%(2420 / 2842)$, time out $43.9 \%(1248 / 2842)$ and sign out $57.7 \%(1642 / 2842)$ were completed. From the three parts of the components, time out was the least implemented from this study (Table 2).

\section{Discussion}

The overall implementation of the WHO surgical safety checklist for surgical patients was found to be $82.1 \%$ and the completeness of the checklist was $30.4 \%$. This study was in line with Amy K. Williams et al and showed that the compliance of the surgical safety checklist was $85 \%{ }^{11}$
Our findings showed that higher implementation of the checklist in comparison to Isabella Epiu et al study and they revealed that the implementation of the checklist was between $0 \%-65 \%$ and their reasons for low achievement were the checklists were not available, not clear and it was also too long. ${ }^{3}$ The reason for the variation was their study focused on only Anesthetist involvement but in our setting the checklist was filled by nurses and the fact that nurses relatively free personnel at the operation theater and also nurses were more aware of the surgical safety checklist. ${ }^{2}$ On the other hand, another study showed a higher percentage of implementation of the checklist, ${ }^{12}$ but their study was only on elective and specific surgery. During specific surgery, the checklist was more implemented. In our study, we include all types of surgery cases.

From our finding the checklist was complete in 30.4\% (all boxes are ticked off) and when we see each component sign in $85.1 \%$, time out in $43.9 \%$, and sign out was $57.7 \%$.

Table I Surgical Safety Checklist Components of 'Sign In' from July 2017 to July 2020 at Debre Tabor Comprehensive Specialized Hospitals $(\mathrm{N}=2842)$

\begin{tabular}{|l|l|l|}
\hline Sign In & Completed Number (\%) & $\begin{array}{l}\text { Missed } \\
\text { Number (\%) }\end{array}$ \\
\hline Has the patient confirmed his/her identity, site, procedure, and consent? & $2840(99.9)$ & $2(0.1)$ \\
Is the site marked? & $2834(99.7)$ & $8(0.3)$ \\
Are the anesthesia equipment and medication checks complete? & $2832(99.6)$ & $10(0.4)$ \\
Pulse oximetry is attached and functional? & $2652(93.3)$ & $190(6.7)$ \\
Does the patient have a known allergy? & $2646(93.1)$ & $196(6.9)$ \\
Does the patient have a difficult airway or aspiration risk? & $2642(92.6)$ & $200(7.4)$ \\
Is the risk of blood loss $>500 \mathrm{~mL}$ and require blood? & $2420(85.1)$ & $422(14.9)$ \\
\hline
\end{tabular}

Table 2 Surgical Safety Checklist Components of 'Time Out' Completeness from July 2017 to July 2020 at Debre Tabor Comprehensive Specialized Hospitals $(\mathrm{N}=2842)$

\begin{tabular}{|l|l|l|}
\hline Time Out & Completed Number (\%) & Missed Number (\%) \\
\hline Confirm all team members have introduced themselves by name and role & $1894(66.6)$ & $948(33.4)$ \\
Confirm the patient's name, procedure, and site of incision & $1864(65.5)$ & $978(34.5)$ \\
Has antibiotic prophylaxis been given within the last 60 min? & $1840(64.7)$ & $1002(35.3)$ \\
Anticipated critical events to the surgeon & $2012(70.7)$ & $830(29.3)$ \\
What are the critical or non-routine steps & $1848(65)$ & $994(35)$ \\
How long will the operation take? & $1648(57.9)$ & $1194(42.1)$ \\
Is the anticipated blood loss $>500$ Is? & $1464(51.5)$ & $1378(48.5)$ \\
Anticipated critical events to the anesthetist & $1640(57.7)$ & $1202(42.3)$ \\
Are there any patient-specific concerns? & $1357(47.7)$ & $1485(52.3)$ \\
Anticipated critical events to the nursing team & $1450(51)$ & $1392(49)$ \\
Sterility confirmed & $2462(86.6)$ & $380(13.4)$ \\
Are there equipment issue or any concern & $2128(74.8)$ & $714(25.2)$ \\
Is essential imaging displayed & $2345(82.5)$ & $497(17.5)$ \\
Does the assigned person put his/her name and signature? & $2212(77.8)$ & $630(22.2)$ \\
\hline
\end{tabular}


Table 3 Surgical Safety Checklist Components of 'Sign Out' Completeness from July 2017 to July 2020 at Debre Tabor Comprehensive Specialized Hospitals $(\mathrm{N}=2842)$

\begin{tabular}{|l|l|l|}
\hline Sign Out & $\begin{array}{l}\text { Completed Number } \\
\text { (\%) }\end{array}$ & Missed Number (\%) \\
\hline The nurse verbally confirms the name of the procedure & $1846(64.9)$ & $996(35.1)$ \\
The nurse verbally confirms Completion of instrument, sponge, needle, and suture counts & $2462(86.6)$ & $380(13.7)$ \\
The nurse verbally confirms Are there any equipment problems to be addressed? & $1842(64.8)$ & $1000(35.2)$ \\
The nurse verbally confirms Specimen labeled correctly & $1642(57.7)$ & $1200(42.3)$ \\
What are the key concerns for the recovery and management of this patient? & $1624(57.1)$ & $1218(42.9)$ \\
Does the assigned person put his/her name and signature? & $1648(57.9)$ & $1194(42.1)$ \\
\hline
\end{tabular}

This finding was related to the work of Ellis et al and showed that the completeness of the checklist was up to $20 \%-60 \%{ }^{8}$ Another study also showed that the completeness of the checklist was $32.6 \%{ }^{13}$ But other studies showed higher checklist completeness and reaches up to $79.3 \%-94 \% .{ }^{14}$ For the good implementation of the surgical safety checklist staff training, in situ demonstrations, awareness-raising on the departmental level, and involvement of all surgical teams were important for the higher implementation of the checklist. ${ }^{15}$ In our finding the checklist was filled by only one department (nursing team). Other studies also showed a higher percentage of completeness of the checklist and increased their performance by giving training and evaluation of the checklist after the intervention. ${ }^{16}$

From the checklist, components sign in and sign out relatively show the higher percentage and time-out were the least implemented form the checklist. On the other hand, another study showed a lower implementation of the sign-out and high implementation in time-out components. ${ }^{17}$ Other studies also show compliance and all the components less than $50 \%$ of implementation and it was associated with a lack of training and awareness on WHO surgical safety checklist, socio-economic norms, and cultural barriers. ${ }^{18}$

From the specific items of the components in our study 'has the patient confirmed his/her identity, site, procedure, and consent' was the most ticked off, and 'What are the key concerns for recovery and management of this patient' was the most poorly ticked off component. Other studies also agree on the least ticked components, ie Recovery concern. ${ }^{8}$ The reason was since the recovery concern discusses and filled by all the surgical team (Surgeon, anesthetists, and nurse) even there were communications the entire checklist filled by nurses. For the better implementation of the surgical safety checklist collaboration of the staff, good communication, training on the importance of checklist, and finally reviewing surgical patients chart regularly were recommended.

\section{Conclusion}

The compliance of the world health organization's surgical safety checklist for the surgical patient at this hospital was good and attached to a surgical patient chart. But the checklist components were not completely assessed and even the time-out component from the checklist was the most neglected part.

\section{Recommendation}

The completeness of the WHO surgical safety checklist was poor so it needs strategies to improve like giving training, awareness creation, and involvement of the surgical team, as well as regular monitoring of the surgical patient's chart, were recommended.

\section{Limitation of the Study}

This is a single-center study and difficult to generalize for other hospitals and the other limitation was the use of secondary data may luck completeness.

\section{Data Sharing Statement}

All the required documents available at the hand of the author and can be supplied upon request.

\section{Acknowledgment}

We want to thank Debre Tabor University for giving us an Ethical clearance during data collection, and the Authorities of Debre Tabor Comprehensive Specialized Hospital and data managers for their permission to do the research.

\section{Author Contributions}

All authors made a significant contribution to the work reported, whether that is in the conception, study design, 
execution, acquisition of data, analysis, and interpretation, or in all these areas; took part in drafting, revising, or critically reviewing the article; gave final approval of the version to be published. And All Authors have agreed on the journal to which the article has been submitted; and agree to be accountable for all aspects of the work.

\section{Funding}

The authors declared that there is no fund obtained for this project.

\section{Disclosure}

The authors confirmed that they have no conflicts of interest for this work.

\section{References}

1. Naidoo M, Moodley J, Gathiram P, Sartorius B. The impact of a modified world health organization surgical safety checklist on maternal outcomes in a South African setting: A stratified cluster-randomised controlled trial. South African Med J. 2017;107 (3):248-257. doi:10.7196/SAMJ.2017.v107i3.11320

2. Hurtado JJD, Jiménez X, Pẽalonzo MA, Villatoro C, De Izquierdo S, Cifuentes M. Acceptance of the WHO surgical safety checklist among surgical personnel in hospitals in Guatemala city. BMC Health Serv Res. 2012;12(1):169. doi:10.1186/1472-6963-12-169

3. Epiu I, Bahe Tindimwebwa JV, Mijumbi C, et al. Working towards safer surgery in Africa; A survey of utilization of the WHO safe surgical checklist at the main referral hospitals in East Africa. BMC Anesthesiol. 2016;16(1):1-7. doi:10.1186/s12871-015-0163-0

4. Weiser TG, Haynes AB, Dziekan G, Berry WR, Lipsitz SR, Gawande AA. Effect of A 19-item surgical safety checklist during urgent operations in a global patient population. Ann Surg. 2010;251 (5):976-980. doi:10.1097/SLA.0b013e3181d970e3

5. Licker M, Francis P, Degiorgi A, Bezzola P. Implementation of the surgical safety checklist in switzerland and perceptions of its benefits: cross-sectional survey. PLoS One. 2014;9(7):1-8.

6. Harrison EM. Pooled analysis of WHO surgical safety checklist use and mortality after emergency laparotomy. BJS. 2019;106:103-112.

Open Access Surgery

Publish your work in this journal

Open Access Surgery is an international, peer-reviewed, open access journal that focuses on all aspects of surgical procedures and interventions. Patient care around the peri-operative period and patient outcomes post-surgery are key topics for the journal. All grades of surgery from minor cosmetic interventions to major surgical procedures are covered. Novel techniques and the utilization of new

Submit your manuscript here: https://www.dovepress.com/open-access-surgery-journa
7. Braham ADL. Application of the WHO surgical safety checklist outside the operating theatre: medicine can learn from surgery. Clin Med (Northfield Il). 2014;14(5):468-474. doi:10.7861/clinmedicine. $14-5-468$

8. Ellis R, Izzuddin Mohamad Nor A, Pimentil I, Bitew Z, Moore J. Improving surgical and anaesthesia practice: review of the use of the who safe surgery checklist in felege hiwot referral hospital, Ethiopia. BMJ Qual Improv Reports. 2017;6:1-8. doi:10.1136/bmjquality. u207104.w6251

9. Melekie TB, Getahun GM. Compliance with surgical safety checklist completion in the operating room of University of Gondar Hospital, Northwest. BMC Res Notes. 2015;8:361. doi:10.1186/s13104-0151338-y

10. WHO Surgical Safety. Checklist and Implementation Manual. World Health Organization; 2008.

11. Williams AK, Cotter RA, Bompadre V, Ph D, Goldberg MJ. Patient safety checklists: do they improve patient safety for. $J$ Pediatr Orthop. 2020;39(5):232-236. doi:10.1097/BPO.0000000000000928

12. Kelly SP, Steeples LR, Smith R. Surgical checklist for cataract surgery: progress with the initiative by the Royal College of Ophthalmologists to improve patient safety. Eye. 2013;27 (7):878-882. doi:10.1038/eye.2013.101

13. Semachew A, Afewerk S, Embiale N. Dataset on utilization of a clinical checklist in the surgical operation in a resource limited settings. Data Br. 2018;21:2562-2566. doi:10.1016/j.dib.2018.11.112

14. Gillespie BM, Harbeck EL, Lavin J, et al. Evaluation of a patient safety programme on surgical safety checklist compliance: A prospective longitudinal study. BMJ Open Qual. 2018;7:3. doi:10.1136/bmjoq-2018-000362

15. Aveling EL, McCulloch P, Dixon-Woods M. A qualitative study comparing experiences of the surgical safety checklist in hospitals in high-income and low-income countries. BMJ Open. 2013;3 (8):1-10. doi:10.1136/bmjopen-2013-003039

16. Sendlhofer G, Mosbacher N, Karina L, Kober B. Implementation of a surgical safety checklist: interventions to optimize the process and hints to increase compliance. PLoS One. 2015;10:1-14. doi:10.1371/ journal.pone. 0116926

17. Pickering SP, Robertson ER, Griffin D, et al. Compliance and use of the World Health Organization checklist in UK operating theatres. $\mathrm{Br}$ J Surg. 2013;100(12):1664-1670. doi:10.1002/bjs.9305

18. Igaga EN, Sendagire C, Kizito S, Obua D, Kwizera A. World health organization surgical safety checklist: compliance and associated surgical outcomes in Uganda's referral hospitals. Anesth Analg. 2018;127(6):1427-1433. doi:10.1213/ANE.0000000000003672 instruments and materials, including implants and prostheses that optimize outcomes constitute major areas of interest. The manuscript management system is completely online and includes a very quick and fair peer-review system, which is all easy to use. Visit $\mathrm{http}: / / \mathrm{www}$.dovepress.com/testimonials.php to read real quotes from published authors. 